\title{
ANTEPROJETO ARQUITETÔNICO DE UMA ESCOLA INFANTIL NA CIDADE DE CAJAZEIRAS-PB
}

\author{
ANTEPROJETO ARQUITETÔNICO DE UMA ESCOLA INFANTIL NA \\ CIDADE DE CAJAZEIRAS-PB
}

\author{
Jefferson Figueiredo Viera ${ }^{1}$ \\ Emanoella Bella Sarmento Salgueiro Eliziário Matias ${ }^{2}$ \\ Ezio Luiz Martins Simões ${ }^{3}$ \\ Rafael Costa de Carvalho Abrantes ${ }^{4}$ \\ Janderson Ferreira Dutra ${ }^{5}$ \\ Marjorie Maria Abreu Gomes de Farias ${ }^{6}$
}

\begin{abstract}
${ }^{1}$ Graduando em Arquitetura e Urbanismo pela Faculdade Santa Maria - FSM;
2 Pesquisadora mestra (2015) pelo Programa de Pós Graduação em Arquitetura e Urbanismo, PPGAU - UFPB. Arquiteta e Urbanista, formada pela Universidade Federal da Paraíba (2011). Colaboradora do Laboratório de Acessibilidade (LACESSE) - UFPB desde 2012 e integrante do grupo de pesquisa Qualidade, Acessibilidade, Tecnologia e Percepção do Ambiente Construído, certificado UFPB e CNPq. Coordenadora e docente do curso de Arquitetura e Urbanismo da Faculdade Santa Maria (FSM) de Cajazeiras, na Paraíba.

${ }^{3}$ Possui graduação em Arquitetura e Urbanismo pelo Centro Universitário de João Pessoa (2012) e mestrado pela Universidade Federal da Paraíba (PPGAU-UFPB). Atualmente é professor nas Faculdades Integradas de Patos-PB (FIP), mas também já trabalhou como professor na Faculdade Santa Maria de Cajazeiras-PB (FSM). Atua principalmente nos seguintes temas: requalificação urbana, bioclimatismo, projeto participativo e arquitetura. Além das atividades profissionais, é acadêmico do curso de Engenharia Civil pela UFCG - CCTA - campus Pombal-PB.

${ }^{4}$ Possui graduação em Arquitetura e Urbanismo pela Universidade Federal da Paraíba (2014) e mestrado em Energias Renováveis pela Universidade Federal da Paraíba (2017) na linha de pesquisa em Meio Ambiente, Economia e Aproveitamento Energético. Atualmente é professor da Faculdade Santa Maria (FSM) em Cajazeiras e das Faculdades Integradas de Patos (FIP). Tem experiência na área de Arquitetura e Urbanismo e Sustentabilidade, com ênfase em Projeto de Arquitetura e Urbanismo.

${ }^{5}$ Possui graduação em Análise e Desenvolvimento de Sistemas pelo Instituto Federal de Educação, Ciência e Tecnologia da Paraíba (2009). Tem pós-graduação em Metodologia do Ensino Superior. Atualmente é professor celetista do ensino superior da Faculdade de Filosofia, Ciências e Letras de Cajazeiras (FAFIC), professor celetista da Faculdade Santa Maria (FSM) de Cajazeiras e professor substituto do Instituto Federal de Educação, Ciência e Tecnologia da Paraíba (IFPB). Tem experiência na área de Informática, com ênfase em Ciência da Computação, atuando principalmente nas seguintes áreas: desenvolvimento de software, engenharia de software, educação à distância e metodologia do ensino.

${ }^{6}$ Arquiteta e Urbanista, graduada pela Universidade Federal da Paraíba (UFPB) (2013) e mestre pelo Programa de Pós-graduação em Arquitetura e Urbanismo da Universidade Federal da Paraíba (PPGAU-UFPB) (2015). Atualmente é professora do curso de Bacharelado em Arquitetura e Urbanismo da Faculdade Santa Maria - Cajazeiras-PB. Tem experiência ministrando aulas e trabalhando com iniciação científica nos seguintes temas: acessibilidade, mobilidade, avaliação pós-
\end{abstract}

Revista Interdisciplinar em Saúde, Cajazeiras, 6 (3): 128-146, jul./set. 2019, ISSN: 2358-7490. 
RESUMO: A educação é essencial no desenvolvimento de uma sociedade. Dessa maneira, a arquitetura tem como objetivo criar um local de estímulos para as atividades de ensino e aprendizagem, contribuindo para a diversidade dos alunos, criatividade individual, coletiva e a troca de conhecimento. Esse trabalho tem como finalidade desenvolver um anteprojeto de uma escola de educação infantil que atenda a cidade de Cajazeiras-PB e região. A compreensão desse espaço, e sua configuração no dia a dia, são fatores primordiais para a concepção de um projeto que venha a atingir os objetivos propostos e, assim, contribuir para o crescimento e desenvolvimento de uma sociedade mais justa. Ratifica-se a importância do espaço escolar no desenvolvimento do comportamento e personalidade dos alunos e usuários, proporcionando educação, ética e valores.

PALAVRAS CHAVE: Arquitetura Escolar, Escola de educação infantil, Espaço escolar.

ABSTRACT: Education is essential in the development of a society. In this way, the architecture aims to create a stimulus site for teaching and learning activities, contributing to the diversity of students, individual creativity, collective and knowledge exchange. This work aims to develop a preliminary project of a kindergarten school that serves the city of Cajazeiras-PB and region. Understanding this space and its day-to-day configuration are key factors in the design of a project that will achieve the proposed objectives and thus contribute to the growth and development of a more just society. The importance of the school space in the development of the behavior and personality of students and users is confirmed, providing education, ethics and values.

KEYWORDS: School Architecture, School of early childhood education, school space.

ocupação, sistema de espaços livres, avaliação pós-ocupação e representação e concepção de projeto. 


\section{INTRODUÇÃO}

A escola é uma das instituições sociais mais importantes no desenvolvimento de uma nação, lugar esse onde as pessoas devem frequentar durante boa parte de suas vidas. A história da educação e da escola conduzem todos os momentos de crescimento do ser humano, a contar da educação primitiva até os moldes da educação aplicada nas escolas atuais.

A relevância pelo tema abordado passa pela exigência de uma reflexão da prática aplicada nos projetos de espaços escolares, onde existem estudos sobre as crianças e adolescentes que frequentaram esses espaços, pensando nas suas necessidades, no seu desenvolvimento, e nas linguagens essenciais do espaço escolar, conectando educação e o entretenimento.

O espaço escolar, de acordo com Kowaltowski (2011), coloca a mostra configurações padronizadas que dificilmente correspondem à atual dinâmica da educação. As necessidades de cada público são diversificadas, seus meios de comunicação são alterados e suas edificações, por pouca variedade e flexibilidade de uso, não acompanham esta demanda, tonando-se uma barreira para a integração, diversidade de escolhas e potencialidades de uma comunidade escolar. Dessa forma, Gifford (2014) expõe uma ideia de que a escola é um lugar que promove o poder de escolha dos alunos na realização de suas atividades e é exatamente nesse ponto que a arquitetura escolar tem como finalidade desenvolver essas oportunidades de ensino e aprendizagem. Além disso, sabe-se que as configurações do espaço influenciam o comportamento das pessoas.

Assim, pode ser verificado que a busca por técnicas de ensino vem se atualizando ano após ano, com o surgimento de novas propostas pedagógicas, transformando o modo de compreender o mundo em uma dinâmica nova, dessa forma, o papel do arquiteto tem uma importância nesse desenvolvimento. Segundo Maia (2018), quando se fala em arquitetura, o tema vai além dos aspectos estéticos, 
pois em um ambiente escolar devem-se levar em consideração parâmetros de conforto ambiental, ergonomia, infraestrutura e implantação do edifício. Para tanto:

O edifício escolar deve ser analisado como resultado da expressão cultural de uma comunidade, por refletir e expressar aspectos que vão além da sua materialidade. Assim, a discussão sobre a escola ideal não se restringe a um único aspecto, seja de ordem arquitetônico, pedagógico ou social: torna-se necessário uma abordagem multidisciplinar, que inclua o aluno, o professor, a área de conhecimento, as teorias pedagógicas, a organização de grupos, o material de apoio e a escola como instituições lugar. (KOWALTOWSKI, 2011, p. 12).

Esse trabalho demonstra a importância de investir na elaboração de uma edificação escolar de qualidade, proporcionando espaços sociais e flexíveis que venham a influenciar no desenvolvimento do processo ensino-aprendizado.

\section{METODOLOGIA}

Para as edificações abordadas nesse ponto do trabalho, foram apontadas referências projetuais que servirão para o desenvolvimento do anteprojeto escolar, e assim, contribuir para o melhor entendimento e realização dos princípios arquitetônicos, desempenho, espaços, sistematização que influenciarão no anteprojeto a ser desenvolvido na sua funcionalidade e estrutura. Sendo apresentados estudos de casos indiretos (pesquisa através de websites) e estudo de caso direto (visita in loco).

Com o seu projeto em 2003 e com sua conclusão em 2004, a escola faz parte de um grupo de quatro projetos pilotos, realizados pela Fundação para o Desenvolvimento da Educação (FDE). A escola vem atender os alunos de $1^{\text {a }}$ a $4^{\underline{a}}$ série do ensino fundamental, com projeto dos arquitetos Marta Moreira, Fernando de Melo e Milton Braga, sendo desenvolvido para atender um conjunto habitacional que foi implantado na região de Campinas pelo governo do estado de São Paulo. 
Com uma área construída de $2.818 \mathrm{~m}^{2}$, possui oito salas de aula, espaços internos e externos de recreação, sala da administração, refeitório, auditório, sendo todos distribuídos em três pavimentos; pavimento setor recreativo; pavimento setor administrativo; pavimento setor das salas de aula, sendo observado que existe um único pavimento que disponibilizará banheiros.

Vindo a expor características que serão utilizadas como referência para o desenvolvimento do anteprojeto escolar, onde a escola Escola de Ensino Fundamental FDE Campinas F1 mostra um projeto que vem a ser utilizado na sua implantação para atender a determinada região em desenvolvimento, usando toda sua área disponível com a construção da edificação, explorando o conforto térmico com a ventilação cruzada e a iluminação natural, com aplicação de elementos vazados.

Mind Makers é uma escola de aprendizagem de programas de computadores para crianças de 7 a 12 anos de idade. O escritório de arquitetura e design Studio dLux projetou a primeira unidade da marca, que está localizada no bairro nobre de Moema, na cidade de São Paulo. O arquiteto Denis Fuzzi, autor do projeto arquitetônico e de interiores, conta que o ideia era implantar um espaço divertido e colorido para os alunos, com o intuito de que toda a programação da escola poderia ter sido feita pelos alunos.

A fachada da Mind Makers é o chamariz da escola. Projetada por um enorme painel laranja usinado em máquina $\mathrm{CNC}$, com o desenho dos circuitos raspberry, iguais aos utilizados pelos alunos em sala de aula. À noite, a fachada fica em evidência com iluminação e coloração marcante, que pode ser controlada por um aplicativo usado pelas próprias crianças.

\section{METODOLOGIA}

A pesquisa corresponde à abordagem qualitativa de carácter exploratório de natureza aplicada. Diante disso, para o desenvolvimento do trabalho, foram utilizadas algumas abordagens e técnicas de pesquisas que auxiliaram na 
complementação de um diagnóstico mais consistente e preciso. O trabalho foi segmentado nas seguintes etapas: pesquisa bibliográfica, projeto correlato, pesquisa institucional, levantamento de dados e condicionantes legais e desenvolvimento do projeto arquitetônico.

Como forma de fundamentação teórica, e para dar início às considerações da pesquisa e ampliar horizontes, foi realizado um primeiro contato com os temas citados anteriormente, através de livros, revistas de plataforma online, dissertações e legislações vigentes.

Foram escolhidos e analisados projetos escolares de nível infantil, de formas indiretas (web site) e diretas (visita in loco na cidade de Sousa-PB) para entendimento dos princípios arquitetônicos sobre o tema abordado, assim como o funcionamento organizacional e espacial.

$\mathrm{Na}$ etapa de levantamento de dados, foram realizadas visitas à secretaria de educação para informações sobre o tema abordado, visitas à prefeitura para se obter o levantamento topográfico, informações sobre o bairro em questão, leis vigentes no código de obras da cidade, assim como quaisquer informações que fossem surgindo como dúvidas, já que o site do município não dispõe de todas as informações sobre aspectos legais.

Após várias visitas, em dias e horários alternados, ao terreno escolhido, observaram-se características importantes que serviram para reunir conhecimentos sobre o local referente à direção da predominância dos ventos, insolação, entorno. Em paralelo, foram realizados levantamento fotográfico e medições do dimensionamento do terreno, a fim de registrar informações que ajudariam na concepção e desenvolvimento do projeto.

Nesse ponto do trabalho, foi utilizada para verificação a análise das normas da ABNT e leis vigentes no código de obra da cidade de Cajazeiras-PB e parâmetros oferecidos como base pelo ministério da educação no desenvolvimento da sua infraestrutura, para auxiliar no desenvolvimento do anteprojeto de uma escola infantil, e examinar sua viabilidade no local.

Nessa fase do trabalho, desenvolveu-se um anteprojeto arquitetônico de uma escola infantil, onde foram definidos todos os seus aspectos para um anteprojeto escolar, de acordo com todos os elementos estudados no decorrer do trabalho para 
seu enriquecimento e auxílio no tema abordado, sendo apresentado o anteprojeto através de: desenhos técnicos (plantas, fachadas, cortes, e perspectivas) com auxílio das ferramentas AUTOCAD 2016, SketchUP 2016 e Lumion 6.0, desenvolvido um memorial descritivo para melhor entendimento do anteprojeto.

O anteprojeto da escola infantil foi desemvolvido na cidade de Cajazeiras, município do estado da Paraíba, a uma distância de 468 quilômetros da capital João Pessoa, situando-se a oeste do estado.

O terreno escolhido para desenvolvimento da proposta do anteprojeto da escola infantil fica localizado no Bairro Jardim Adalgiza, situado na região leste da cidade, tendo como vizinho os bairros: Centro, Edmilson Cavalcante, Deodato Cartaxo de Sá e Jardim Oasis. Seus limites iniciam-se na confluência do canal Santa Cecilia com Av. CMTE Vital Rolim, no sentido leste com Av. Jose Rodrigues de Sá, sendo considerado um bairro residencial em desenvolvimento de classe média alta.

Como pode ser verificado no mapa 1 , o levantamento topográfico fornecido pela prefeitura de Cajazeiras-PB demonstra que 0 terreno escolhido para implantação do anteprojeto escolar é plano e que os desníveis só estrarão presentes em outros setores da região.

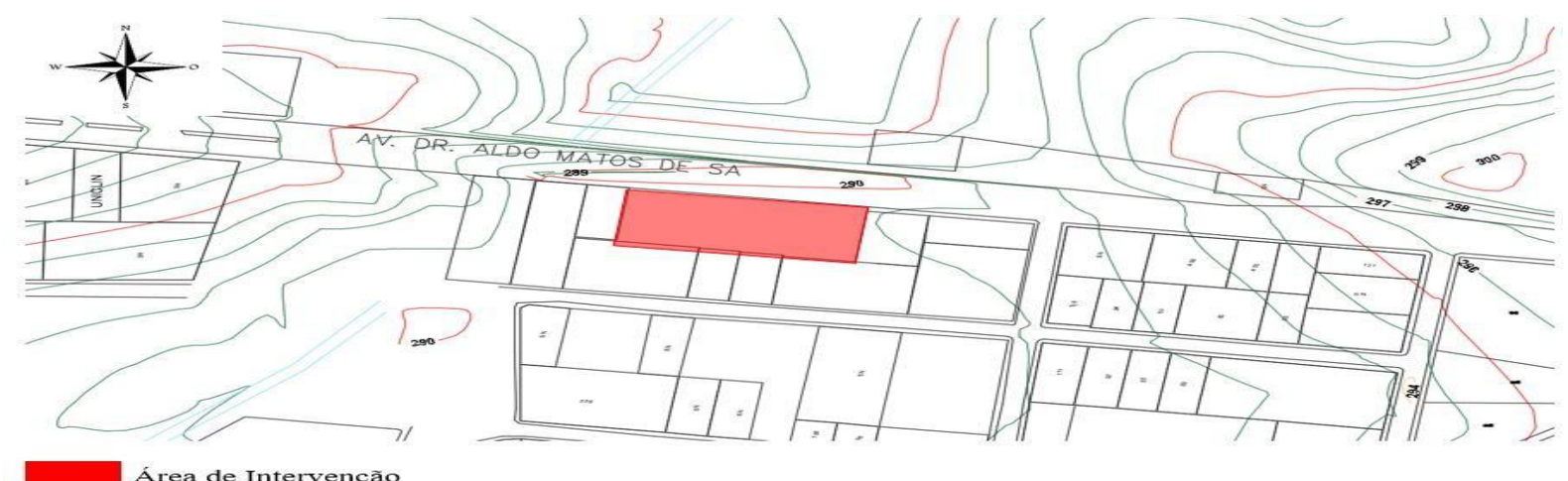

Mapa 1: Levantamento topográfico da região.

Fonte: Prefeitura Municipal de Cajazeiras-PB, 2019. Adaptado pelo autor, 2019.

O desenvolvimento de uma unidade escolar demanda planejamento e envolve estudos para elaboração do projeto arquitetônico, propõe incorporar metodologia e incluir as necessidades dos usuários, dessa forma seguindo os parâmetros de 
indutor de politização educacional e de componentes de diretrizes para educação, com papel fundamental do Ministério da Educação (MEC).

\section{RESULTADOS E DISCUSSÃO:}

A proposta inicial tomou como conceito a criação de ambientes bem setorizados espacialmente, tornando fácil e intuitiva a circulação e interação com as áreas de vivência, além de espaços iluminados e ventilados, proporcionando aos usuários um local agradável e estimulante.

No Brasil, a Lei de Diretrizes e Bases da Educação Nacional chama o equipamento educacional que atende crianças de 0 a 3 anos de CRECHE. $O$ equipamento educacional que atende crianças de 4 a 6 anos chama-se PRÉESCOLA. Na educação infantil, a avaliação precisa de acompanhamento e registro do seu desenvolvimento, sem o objetivo de promoção, mesmo para o acesso ao ensino fundamental. Recentes medidas legais modificaram 0 atendimento das crianças PRÉ-ESCOLA, pois alunos com seis anos de idade devem obrigatoriamente estar matriculados no primeiro ano do Ensino Fundamental.

Os dispositivos legais que estabeleceram as modificações citadas são os seguintes: Projeto de Lei no 144/2005, aprovado pelo Senado em 25 de janeiro de 2006, que estabelece a duração mínima de 9 (nove) anos para o ensino fundamental, com matrícula obrigatória a partir dos 6 (seis) anos de idade. Essa medida deverá ser implantada até 2010 pelos Municípios, Estados e Distrito Federal. Durante esse período, os sistemas de ensino terão prazo para adaptar-se ao novo modelo de pré-escolas, que agora passarão a atender crianças de 4 e 5 anos de idade. Diante disso, foi pensado no programa de necessidades a seguir: 
Tabela 1: Programa de Necessidades.

SETOR SERVIÇO

\begin{tabular}{|c|c|c|}
\hline AMBIENTE & QUANTIDADE & ÁREA $\left(\mathrm{m}^{2}\right)$ \\
\hline DEPÓSITO & 1 & $17,50 \mathrm{~m}^{2}$ \\
\hline COZINHA & 1 & $22,70 \mathrm{~m}^{2}$ \\
\hline DESPENSA & 1 & $4,60 \mathrm{~m}^{2}$ \\
\hline REFEITORIO & 1 & $17,15 \mathrm{~m}^{2}$ \\
\hline VESTIARIO MASCULINO & 1 & $11,20 \mathrm{~m}^{2}$ \\
\hline VESTIARIO FEMININO & 1 & $10,95 \mathrm{~m}^{2}$ \\
\hline LAVANDERIA & 1 & $15,22 m^{2}$ \\
\hline ROUPARIA & 1 & $6,47 \mathrm{~m}^{2}$ \\
\hline $\mathrm{DML}$ & 1 & $7 m^{2}$ \\
\hline \multicolumn{3}{|c|}{ SETOR VIVÊNCIA } \\
\hline AMBIENTE & QUANTIDADE & ÁREA $\left(\mathrm{m}^{2}\right)$ \\
\hline PATIO COBERTO & 1 & $203 m^{2}$ \\
\hline PLAYGROUND & 1 & $92,90 \mathrm{~m}^{2}$ \\
\hline ÁREA VERDE & & $212 m^{2}$ \\
\hline \multicolumn{3}{|c|}{ SETOR ADMINISTRATIVO } \\
\hline AMBIENTE & QUANTIDADE & ÁREA $\left(\mathrm{m}^{2}\right)$ \\
\hline DIRETORIA & 1 & $10,81 \mathrm{~m}^{2}$ \\
\hline SECRETÁRIA & 1 & $21 \mathrm{~m}^{2}$ \\
\hline ARQUIVO & 1 & $9,55 \mathrm{~m}^{2}$ \\
\hline CORDENAÇÃO PEDAGÓGICA & 1 & $10,80 \mathrm{~m}^{2}$ \\
\hline SALA DOS PROFESSORES & 1 & $40,64 m^{2}$ \\
\hline SANITARIO & 2 & $3,24 m^{2}$ \\
\hline SANITARIO PNE & 2 & $4,60 \mathrm{~m}^{2}$ \\
\hline \multicolumn{3}{|c|}{ SETOR PEDAGOGICO } \\
\hline AMBIENTE & QUANTID ADE & ÁREA $\left(\mathrm{m}^{2}\right)$ \\
\hline SALA PRÉ ESCOLA & 6 & $37,50 \mathrm{~m}^{2}$ \\
\hline SALA MULTIUSO & 1 & $57,93 m^{2}$ \\
\hline CRECHE ATIVIDADE & 2 & $26,80 \mathrm{~m}^{2}$ \\
\hline SALA REPOUSO & 2 & $18,60 \mathrm{~m}^{2}$ \\
\hline SANITARIO INFANTIL & 2 & $22,65 \mathrm{~m}^{2}$ \\
\hline SANITARIO INFANTIL PNE & 2 & $6,37 \mathrm{~m}^{2}$ \\
\hline FRALDÁRIO & 2 & $9,25 m^{2}$ \\
\hline LACTÁRIO & 1 & $8,35 \mathrm{~m}^{2}$ \\
\hline ALIMENTAÇÃO & 1 & $14,83 \mathrm{~m}^{2}$ \\
\hline
\end{tabular}

Fonte: Arquivo pessoal, Jefferson Figueiredo, 2019

O projeto compõe-se de: 
- $\quad$ Prancha 1/5, Planta de localização, Planta de Situação e coberta.

- Prancha 2/5, Planta de Localização, Planta Baixa, Quadro de esquadria, Quadro de áreas.

- $\quad$ Prancha 3/5, Planta de Localização, Planta Baixa - Estrutura Marcação de Pilar, Cortes AA, Corte BB.

- Prancha 4/5, Planta de Localização, Fachada Norte, Fachada Sul, Fachada Leste e Fachada Oeste, Perspectiva Externa.

- Prancha 5/5, Planta de Localização, Planta de Layout, Perspectiva Externa, Perspectiva Interna.

A proposta foi desenvolvida em um único pavimento, sendo composta por quatro setores: Setor Administrativo (Recepção, Secretaria, Arquivo, Diretoria, Coordenação pedagógica, Sala dos Professores, Sanitários), Setor Pedagógico (Sala da Pré Escola, Creche, Sala Multiuso, Repouso, Lactário, Alimentação, Sanitário infantil), Setor de Serviço (Cozinha, Refeitório, Deposito, Lavanderia, DML), Setor de Vivencia (Pátio Coberto, Playground) (Figura 18). Edificação com área total de $2.213 \mathrm{~m}^{2}$, com taxa de ocupação de $58 \%$.

Ocorreu uma consulta à Prefeitura de Cajazeiras-PB. Nesse encontro, o arquiteto responsável forneceu o código de obras da cidade, referente à Lei $n^{\circ}$ 644/76 de 14 de junho de 1978, deixando alguns pontos bem claros nesse contato, que serão utilizados nesse trabalho, referentes à taxa de ocupação aceitável pela prefeitura, podendo exceder $10 \%$ do permitido, e que em um dos muros é permitido colar a edificação cerca de $40 \%$ de acordo com seu dimensionamento. Esse contexto não está descrito no código de obras, mas provém de uma política interna utilizada pela prefeitura.

As paredes serão de alvenaria de tijolos cerâmicos oito furos com dimensões

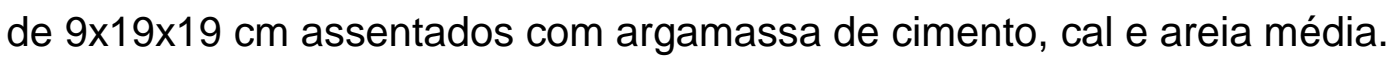


Figura 1: Tijolo cerâmico 8 furos.

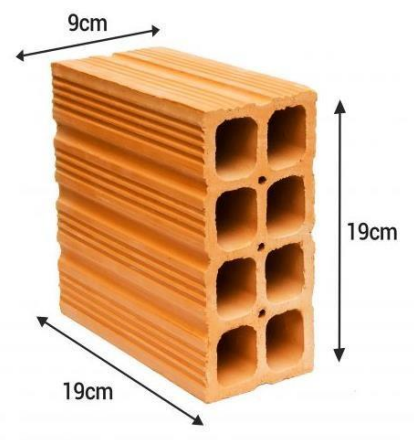

Fonte: Disponível em: .

As estruturas da coberta contarão com uma laje maciça formada por uma malha de vigas de aço preenchidas de concreto, sendo totalmente impermeabilizado e com área total de $1.023 \mathrm{~m}^{2}$ (Figura 2).

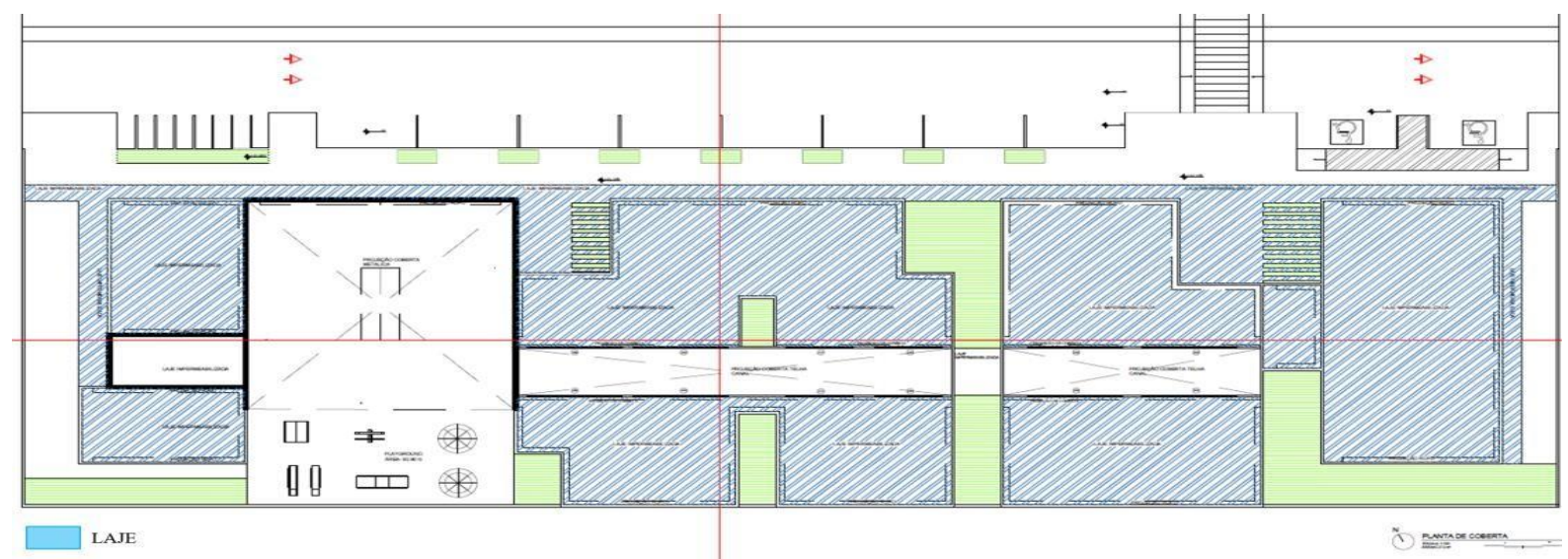

Figura 2: Planta de coberta, Área delimitação de laje.

Fonte: Arquivo pessoal, Jefferson Figueiredo, 2019.

A estrutura da cobertura será executada com três tipos de telhado: Telha metálica sanduíche termo-acústica, sobre uma estrutura metálica com perfil U4"x2,65mm e inclinação de 10\%, para proteção da laje das águas pluviais. Telha cerâmica e telha de vidro moema, sobre uma estrutura em madeira com inclinação de $30 \%$, para proteção do corredor de interligação dos ambientes. 


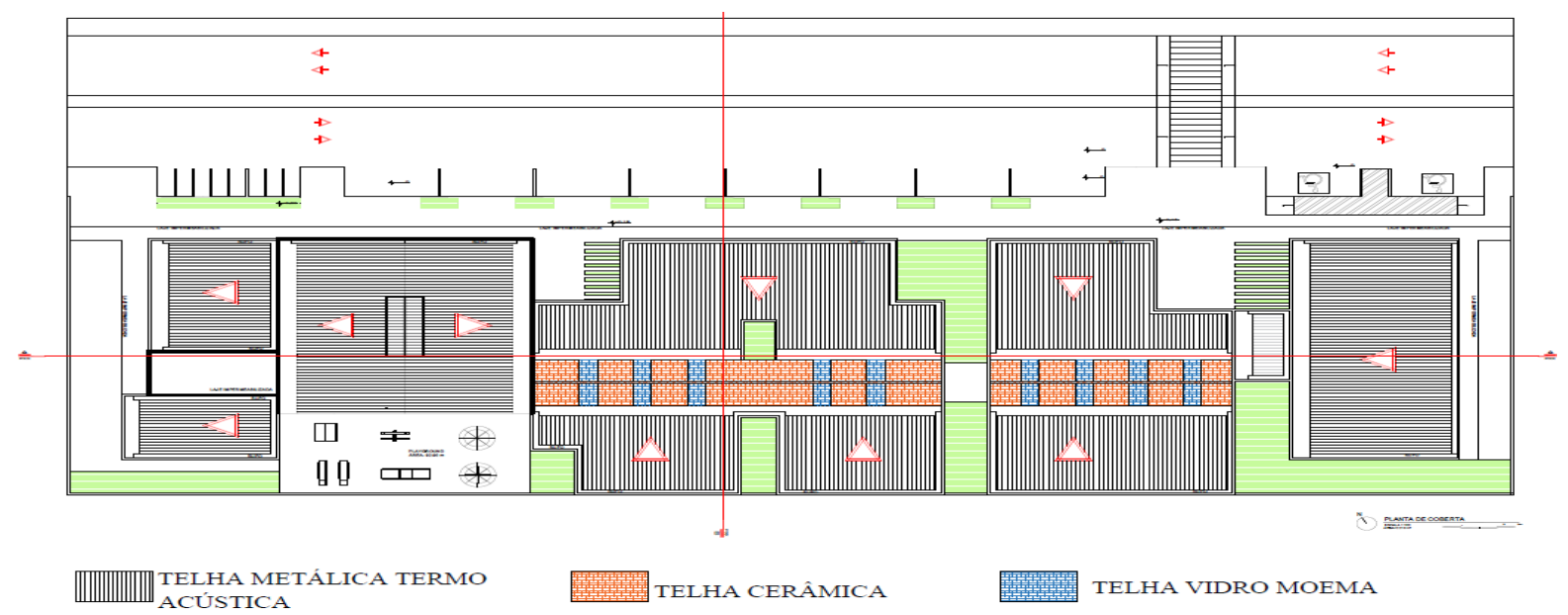

Figura 3: Planta de coberta, Telhado

Fonte: Arquivo pessoal, Jefferson Figueiredo

Tijolo intertravado na cor cinza, sendo assentado em toda a calçada de passeio e em dois corredores externos da edificação, com blocos pré-moldados de rápida execução, possui vida útil longa, baixa manutenção e alta capacidade de drenagem das águas das chuvas, totalizando uma área de $390 \mathrm{~m}^{2}$.

Estacionamento contará com oito vagas de moto com dimensionamento de $95 \mathrm{~cm} \times 2.5 \mathrm{~m}$ e 10 vagas de carro, sendo duas exclusivas para pessoas com deficiência ou mobilidade reduzida, com dimensionamento de $2.30 \mathrm{~m} \times 5.20 \mathrm{~m}$ (Figura 26).

Todas as paredes de alvenaria externas da edificação receberão acabamento final em pintura acrílica semibrilho com uma parte da edificação sendo pintada na cor branca e a outra, na cor amarela. Na fachada, será instalada uma estrutura metálica em metalon 4 polegadas galvanizado, com objetivo de proteção das aberturas: janelas e espaços vazados na edificação, remetendo suas cores a do arco-íris, dando esse tom mais alegre na edificação. 

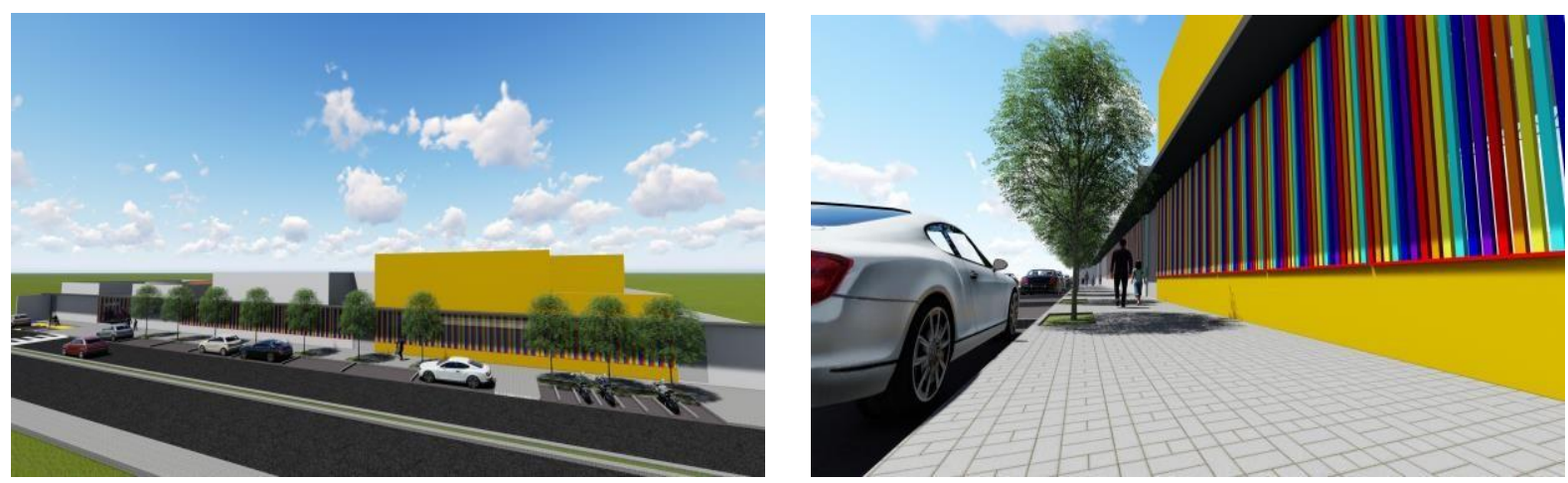

Figura 4: Perspectiva externa.

Fonte: Arquivo pessoal, Jefferson Figueiredo, 2019.

Piso porcelanato fosco com dimensionamento $40 \times 40$, tratado em toda edificação, especificado no projeto arquitetônico, instalado com cimento cola.

Cerâmica como revestimento das paredes deverá ser aplicada após o emboço, com argamassa ou pasta de cimento cola até a altura do peitoril 1,20 em locais como; corredores, pátio coberto, playground e muros da edificação. $E$ até $1,50 \mathrm{~m}$ na sala pré escola, creche, sala multiuso, sala de repouso. Deverá ser de boa qualidade, com dimensões $20 \times 20 \mathrm{~cm}$.

As paredes serão todas emassadas e pintadas com tinta acrílica semibrilho na cor branco neve.
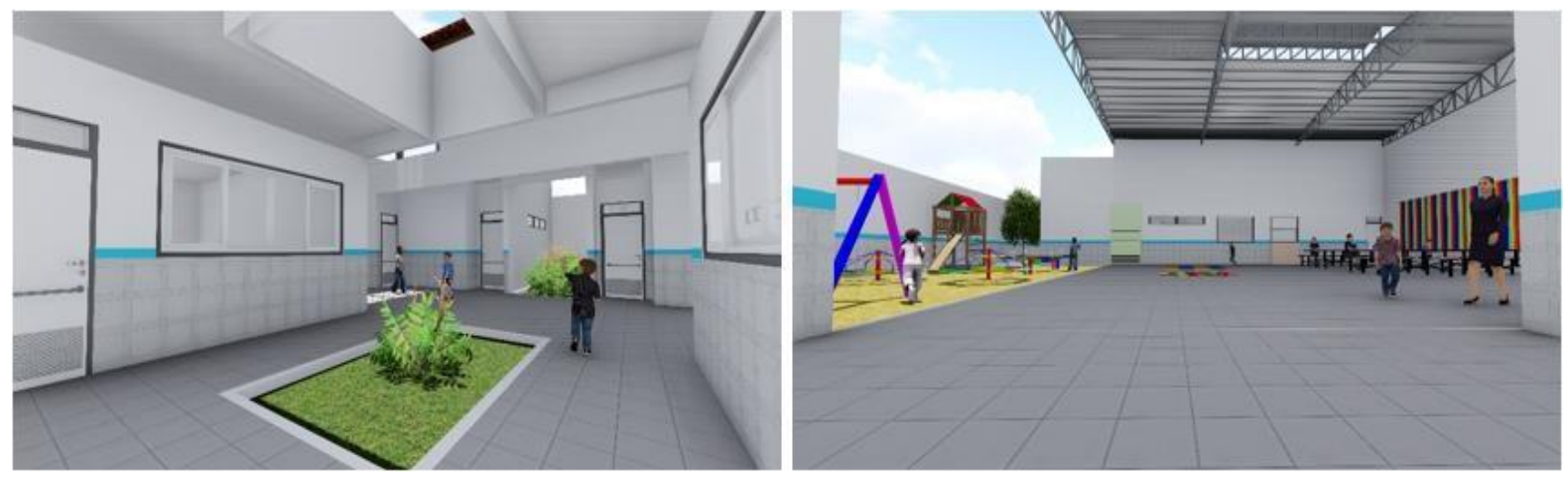

Figura 5: Perspectiva Interna

Fonte: Arquivo pessoal, Jefferson Figueiredo, 2019

Foi pensado no forro rebaixado de gesso em placas fixado à laje com pé direito de $3 \mathrm{~m}$, e o acabamento será em pintura acrílica acabamento fosco na cor brando neve. 
A setorização dos banheiros ocorreu em cinco setores: Sanitário Infantil Masc./Fem., com total de seis sanitários, seis chuveiros e seis pias com altura e dimensões ajustada a padrões infantis. Sanitário Infantil PNE Masc./Fem., com total de dois sanitários, dois chuveiros, duas pias e barras de apoio com altura e dimensões ajustada a padrões infantil e seguindo a norma da ABNT NBR 9050. Sanitário Masc./Fem., com total de dois sanitários e duas pias. Sanitário PNE Masc./Fem., com total de dois sanitários, duas pias e barras de apoio seguindo a norma da ABNT NBR 9050. Vestiário para Funcionários Masc./Fem., com total de três sanitários, quatro chuveiros e quatro pias.

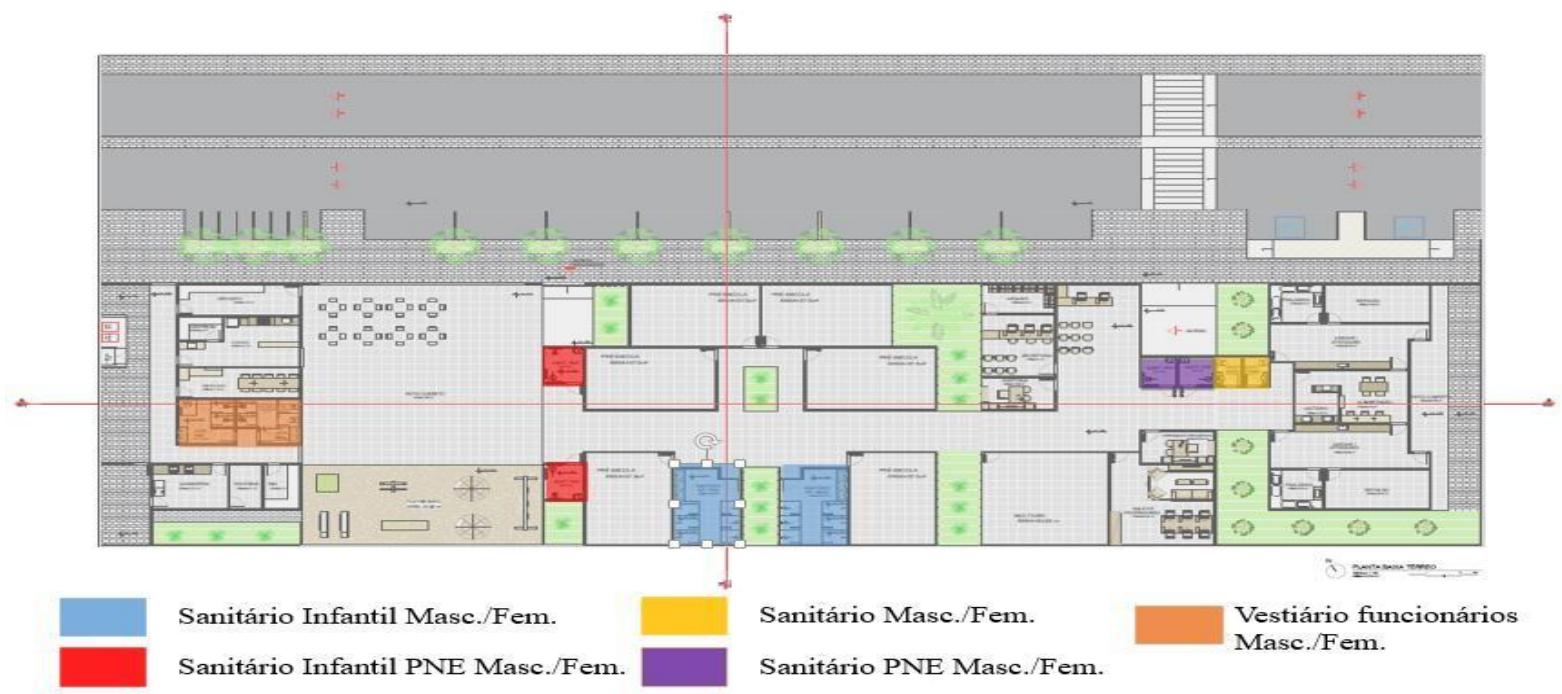

Figura 6: Planta Baixa, Marcação dos Banheiros.

Fonte: Arquivo pessoal Jefferson Figueiredo, 2019.

- $\quad$ Piso porcelanato fosco no dimensionamento $40 \times 40$, tratado em toda edificação especificado no projeto arquitetônico, colocado com cimento cola.

- Cerâmica porcelanato polido como revestimento das paredes deverá ser aplicada após o emboço, com argamassa ou pasta de cimento cola até a altura do forro. Ser de boa qualidade, com dimensões $40 \times 40 \mathrm{~cm}$.

- Granito sendo utilizado na bancada da pia e no divisor dos box entre sanitários e chuveiros, sendo especificados no projeto arquitetônico.

- $\quad$ Teto sendo colocado o forro rebaixado de gesso em placas fixado à laje com pé direito de $3 \mathrm{~m}$, o acabamento será em pintura acrílica em acabamento fosco na cor branco neve. 
Para a composição do paisagismo foi pensado em uma composição de formas simples, utilizando arborização bastante comum na região. Nesses espaços, serão inseridos grama-esmeralda e arvores de médio porte, totalizando uma área verde de $338,10 \mathrm{~m}^{2}$.

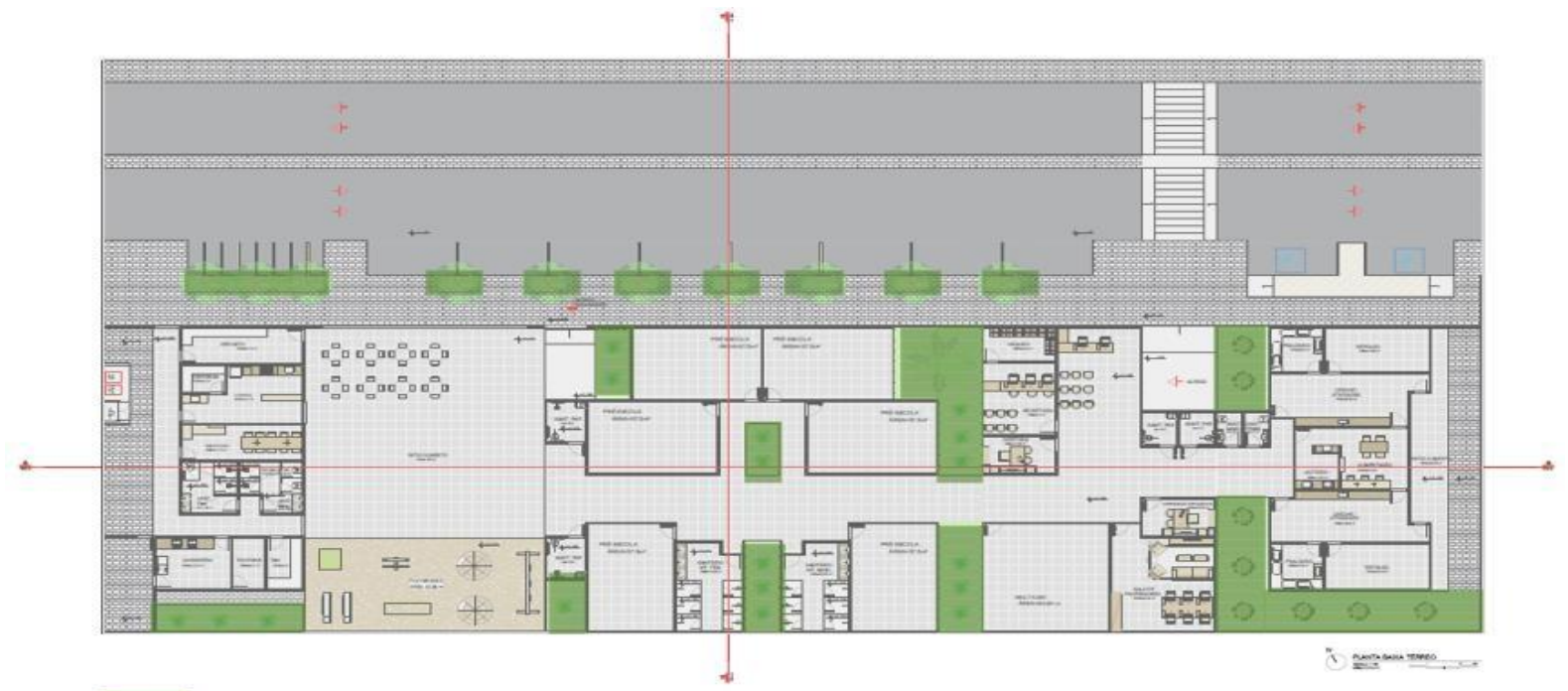

ÁREA VERDE

Figura 7: Planta Baixa, Demarcação Área Verde.

Fonte: Arquivo pessoal, Jefferson Figueiredo, 2019.

A edificação possui acessos principal e secundário, além de contar com entradas de serviço e saída de emergência. A circulação é distribuída pela zona de serviço, que contém corredores com largura de $1,50 \mathrm{~m}$, sendo restrita para funcionários e pela zona de circulação dos usuários, que contém corredores com largura de $3 \mathrm{~m}$. Assim respeitando as normas existentes sobre dimensionamento ABNT NBR 9050. 


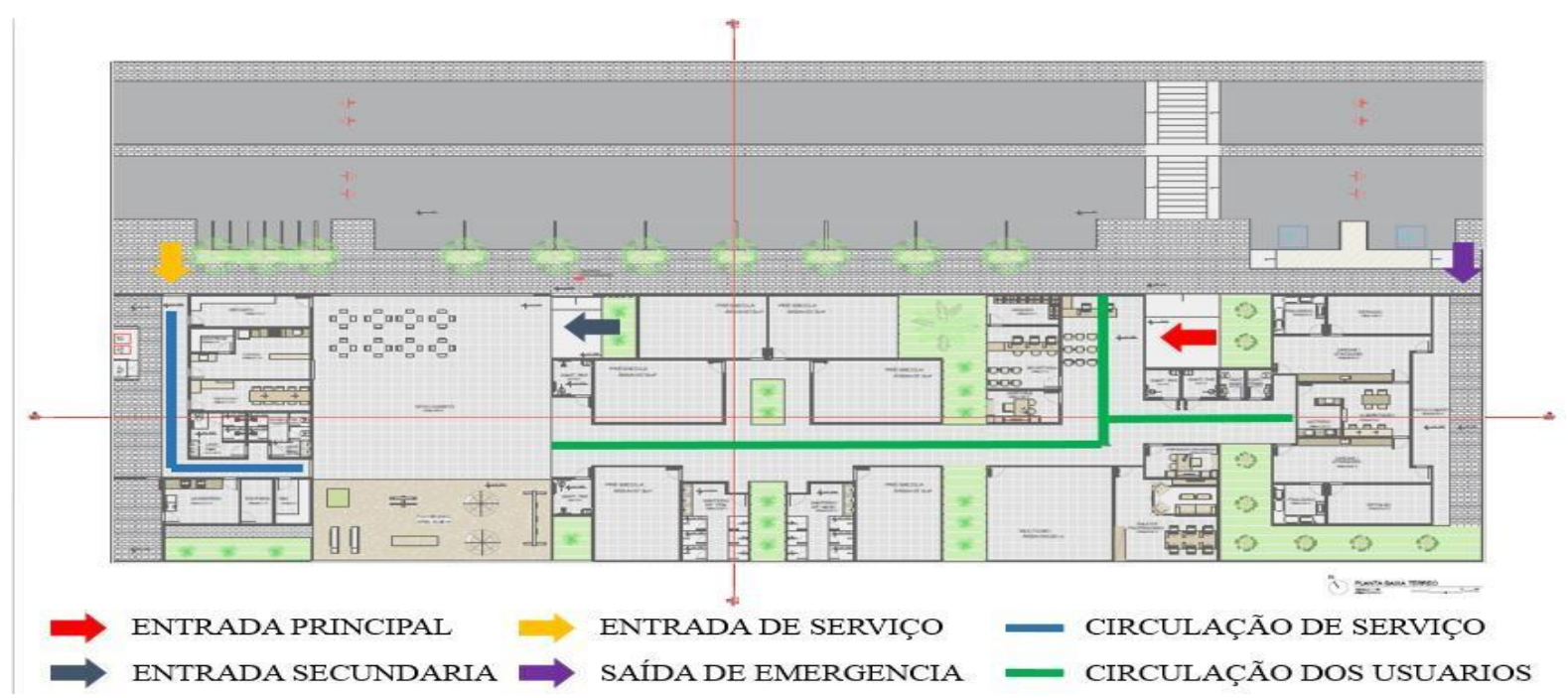

Figura 8: Setorização de acessos e circulação.

Fonte: Arquivo pessoal Jefferson Figueiredo, 2019.

O projeto de instalação para o uso de gás natural adequou-se aos locais onde os aparelhos serão instalados, garantindo a segurança, o conforto e a melhor eficiência no uso do aparelho. A adequação do ambiente realizou-se de acordo com a norma NBR 13103, a qual especifica os requisitos mínimos exigíveis para projeto, construção, ampliação, reforma e instalação de aparelhos a gás, etc. A casa do gás está inserida próxima à entrada de serviço, para facilitar troca do gás e eventual manutenção.

Todo o lixo e resíduos da edificação têm seu local devidamente colocado na lixeira, próximo à entrada de serviço, local pensado ao posicionar o sentido oposto à ventilação, não levando possível mal cheiro para a escola e facilitando a coleta do carro do lixo e catadores. 


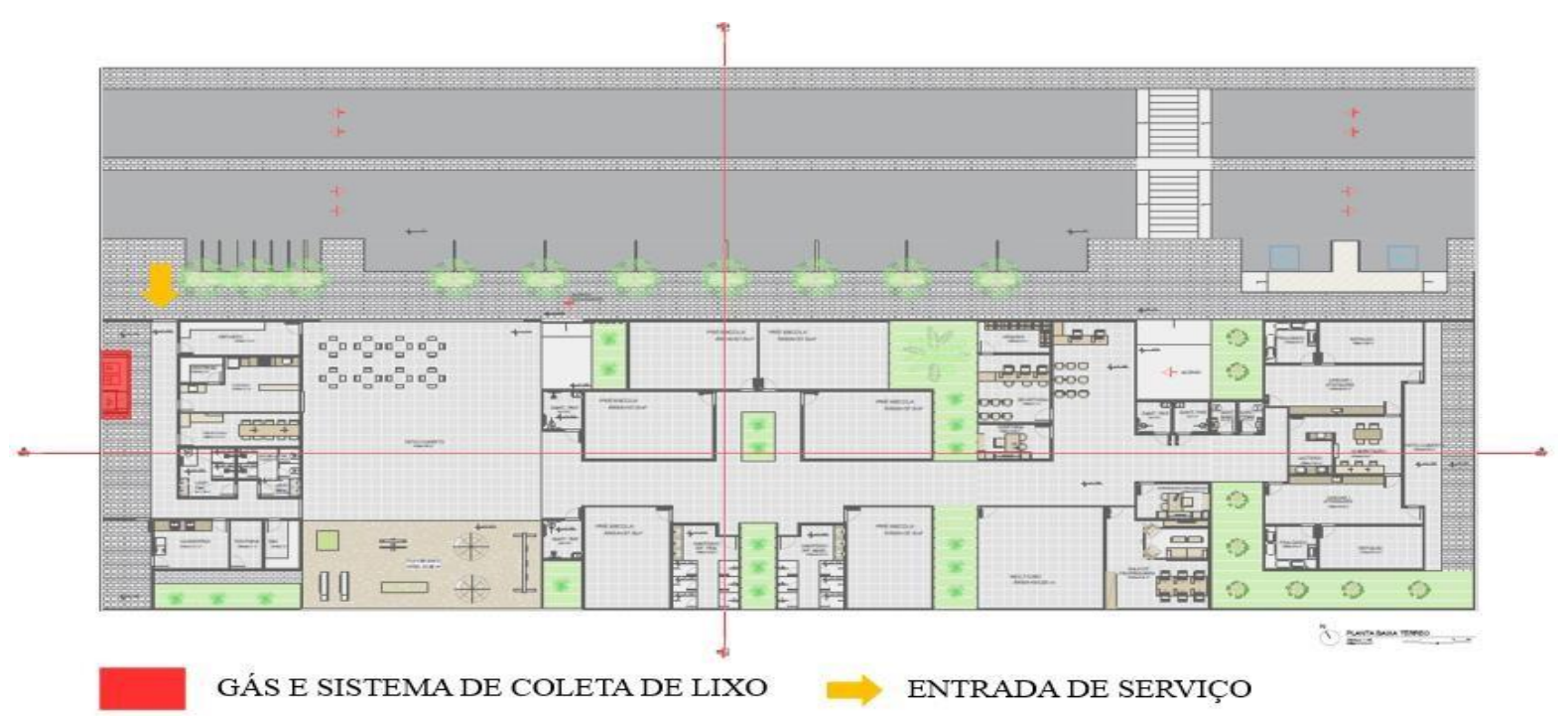

Figura 9: Demarcação do sistema de coleta de lixo e gás.

Fonte: Arquivo pessoal, Jefferson Figueiredo, 2019.

\section{CONSIDERAÇÕES FINAIS}

Ratifica-se a importância da arquitetura na elaboração de um anteprojeto escolar, tendo como finalidade realizar uma obra que atenda às necessidades dos alunos e usuários e também aos requisitos básicos de uma escola confortável. Assim, o arquiteto deve ter total conhecimento sobre o ambiente a ser planejado, otimizando os espaços disponíveis e, dessa forma, criando uma relação entre o espaço escolar, a criança e todos os funcionários que irão conviver naquele meio.

Após realizar um estudo de campo na cidade de Cajazeiras, percebe-se a real necessidade de elaborar um espaço escolar qualificado, proporcionando conforto, acessibilidade, educação e humanização da criança. Por isso, o objetivo desse trabalho foi desenvolver um anteprojeto de uma escola de educação infantil na cidade de Cajazeiras. Utilizando-se de formas e desenhos simples para elaboração do anteprojeto arquitetônico, seguindo as normas e propostas oferecidas pelos órgão responsáveis sobre o assunto, tornando a edificação um local acessível ao público alvo. 


\section{REFERÊNCIAS BIBLIOGRÁFICAS}

ARQUITETURA Escolar: acessibilidade. Disponível em: <https://projetosdearquitetura.blog.br/acessibilidade-nas-escolas/?fbclid=IwAR2-rBGuamK8vDYi9RmzFelyzPkkaqXA-JHxYtUj9YkmMf0YP3qbDth9OY>. Acesso em: 17 nov. 2018.

ASSOCIAÇÃO BRASILEIRA DE NORMAS TÉCNICAS. NBR 9050: Acessibilidade a edificações, mobiliário, espaços e equipamentos urbanos. Rio de Janeiro: ABNT, 2015.

ASSOCIAÇÃO BRASILEIRA DE NORMAS TÉCNICAS. NBR 16537: Acessibilidade Sinalização tátil no piso Diretrizes para elaboração de projetos e enstalação . Rio de Janeiro: ABNT, 2016.

ARGAN, G. C. On the typology of Architecture. Architectural Design. v. 33, n. 12, p. 564- 565, 1963.

AZEVEDO, G. A. N. Arquitetura escolar e educação: um modelo conceitual de abordagem interacionista. 2002. Tese (Doutorado). Instituto Alberto Luiz Coimbra de Pós-Graduação e Pesquisa de Engenharia, Universidade Federal do Rio de Janeiro, Rio de Janeiro. 2002.

BRASIL. Ministério da Educação (MEC). Educação Integral. Brasília, 2009.

INSTITUTO BRASILEIRO DE GEOGRAFIA E ESTATÍSTICA. Cartilha Censo 2010. Disponível em: <www.pessoascomdeficiencia.gov.br>. Acesso em: novembro. 2018.

DELIBERADOR, M. S. Parâmetros da arquitetura escolar e o jogo de cartas como ferramenta de apoio ao desenvolvimento do programa arquitetônico. 2016. Tese (Doutorado em Engenharia Civil e Arquitetura) - Universidade Estadual de Campinas. Campinas, 2016.

ESCOLA de Ensino Fundamental FDE Campinas F1. Disponível em: <https://www.archdaily.com.br/br/01-25980/escola-de-ensino-fundamental-fde-campinas-f1$\mathrm{mmbb}>$. Acesso em: novembro. 2018.

ESQUADRIAS de alumínio e vidro. Disponível em: <http://www.construcaoemvidros.com.br/esquadrias-de-aluminio-e-vidro/>. Acesso em: 10 mar. 2019.

FUNDAÇÃO Nacional de Desenvolvimento da Educação. Brasilia, 2006. Disponível em: https://www.fnde.gov.br/programas/proinfancia. Acesso em: 20 fev. 2019.

ADMINISTRAÇÃO FRANCISCO MATIAS ROLIM. Lei no 644/76 de 14 de junho de 1978 no Lei $n^{\circ}$ 644/76 de 14 de junho de 1978, de 14 de junho de 1978. Jornal Oficial do Município de Cajazeiras, 20 de Fevereiro de 1979. Cajazeiras-PB, 1978.

FUNDESCOLA - Fundo de Fortalecimento da Escola/DIPRO. In: Manual para adequação de prédios escolares. Brasilia: Ministério da Educação, 2006.

PREFEITURA Municipal de Cajazeiras. Historia. Disponível em: <https://cajazeiras.pb.gov.br/omunicipio/historia/>. Acesso em: novembro. 2018.

GODOY, Alessandra Braz de. Escola de educação infantil e os espaços de aprendizagem. 2017. 152 f. Tese (Doutorado em Arquitetura e Urbanismo) - Centro Universitário Senac. São Paulo, 2012. 
GHIRALDI, André Luiz Dias. Análise de acessibilidade em calçadas, vias públicas e prédios públicos na cidade de Doutor Camargo-PR. 2014. 97 f. Monografia (Especialização em Engenharia Civil) - Universidade Tecnológica Federal do Paraná. Campo Mourão, 2014.

LOJA de Telha de Vidro Moema. Disponível em: <http://www.madeireiragoncalez.com.br/madeireira/telhas/telha-de-barro/loja-de-telha-de- vidromoema>. Acesso em: 10 mar. 2019.

MAIA, Mirella Bezerra. Centro de Educação Infantil Barroso. 2018. 162 f. Tese (Doutorado em Arquitetura e Urbanismo) - Centro Universitário 7 de Setembro. Fortaleza, 2018.

MARIN, A. A. Pesquisa em educação ambiental e percepção ambiental. Pesquisa em educação ambiental. v. 3, n. 1, p. 203-222, 2008.

MIND Makers. 2016. Disponível em: <https://www.galeriadaarquitetura.com.br/projeto/studiodlux_/mind-makers/3627>. Acesso em: novembro. 2018.

NASCIMENTO, M. F. P. do. Arquitetura para educação: a construção do espaço para a formação do estudante. 2012. Dissertação (Mestrado) - Faculdade de Arquitetura e Urbanismo, Universidade de São Paulo, São Paulo, 2012.

PARÂMETROS Básicos de Infra-estrutura para Instituições de Educação Infantil. In: PARÂMETROS Básicos de Infra-estrutura para Instituições de Educação Infantil. Brasília: Ministério da Educação, 2006.

PISO intertravado para calçadas. Disponível em: $<1$-piso-intertravado-para-calcadas-conhecaas-especificacoes-tecnicas-212948-1.aspx>. Acesso em: 10 mar. 2019.

REBOCO de parede com argamassa.Disponível em: <https://cimentomaua.com.br/produtos/>. Acesso em: 23 maio 2019.

TELHA Galvanizada Termoacústica. Disponível em: <telha-galvanizada-termoacustica>. Acesso em: 10 mar. 2019.

PRINCIPAIS tipos de telhas de cerâmica para não errar no telhado. Disponível em: $<$ https://www.coberturasleves.com.br/6-principais-tipos-de-telhas-de- ceramica-para-nao-errarno-telhado/>. Acesso em: 10 mar. 2019. 